\title{
Role of Renal Biopsy in Managing Paediatric Renal Disease in a Tertiary Care Setting
}

\section{Shankar Prasad Yadav and Jitendra Thakur}

Department of Paediatrics, BP Koirala Institute of Health Sciences, Dharan, Nepal

\section{Correspondence:}

Shankar Prasad Yadav,

Paediatric Nephrologist,

Department of Paediatrics,

BP Koirala Institute of Health Sciences,

Dharan, Nepal.

Email: shankardharan@gmail.com

DOI: $10.3126 /$ jnps.v41i2.29485

Submitted on: 2020-06-11

Accepted on: 2020-10-04

\section{Acknowledgements: None}

Funding: Nil

Conflict of Interest: None declared

Permission from IRB: Yes
To cite this article: Yadav SP, Thakur J. Role Of Renal Biopsy In Managing Pediatric Renal Disease In A Tertiary Care Setting. J Nepal Paediatr Soc. 2021;41(2):247-52.

\section{ABSTRACT}

Introduction: The contribution of renal biopsy is of major importance in many paediatrics renal diseases. This prospective study analysed the clinic-pathological spectrum of the biopsied cases, complications related to renal biopsy and its effect on management.

Methods: USG guided percutaneous renal biopsy was performed in indicated children. Laboratory findings, complications of the procedure, histological diagnosis and its effect on management were obtained from all patients who underwent renal biopsy from April 2019 to March 2020. The data were finally analysed using descriptive statistics.

Results: Total 50 cases were enrolled during the study period. There were 24 males and 26 females with age range from two to 16 years. The common indications for biopsy were acute nephritic syndrome ( 25 cases), including both primary glomerulonephritis (11 cases) and secondary glomerulonephritis (14 cases), of which lupus nephritis contributed (11/25) cases, followed by atypical/ steroid resistant or dependent nephrotic syndrome (18 cases). Among primary glomerulonephritis, diffuse proliferative glomerulonephritis was most common pathological finding (11/25). One had crescentric glomerulonephritis. Lupus nephritis predominantly had Class IV/V pathology (6/11). Of 18 nephrotic syndrome cases, nine had minimal-change-disease and five had focal-segmental-glomerulosclerosis. The complications associated with procedure were self-resolving gross hematuria in eight cases, perirenal hematoma requiring plasma transfusion in one case. Adequate renal tissue sample was obtained in 47 of the renal biopsies. Three cases underwent repeat biopsy. Immunosuppressive therapy was altered as per the biopsy report among 18 cases.

Conclusions: Our study showed that renal biopsy is a safe, reliable and effective technique in children. It resolutes many diagnostic dilemma and helps in effective management.

Key words: paediatrics; renal biopsy; ultrasonography 


\section{INTRODUCTION}

Ultrasound guided percutaneous renal biopsy has emerged as a safe procedure and is efficacious in obtaining renal tissue for pathological evaluation. ${ }^{1,2}$ Renal biopsy provides a window to diagnose, prognosticate and manage many renal conditions. Clinico - pathological dissociation is commonly observed among renal disease either it is vasculopathy, glomerulopathy or tubulopathy. It is often difficult to make an assumption on the pathology in the kidney looking at the clinical signs or investigation and management is often linked up with pathological findings. ${ }^{3,4}$ Hence, performing renal biopsy in indicated cases is a gold standard investigation in managing renal conditions. However, performing renal biopsy is often challenging because of risk related to anesthesia and haemorrhage. ${ }^{5}$ We conducted this prospective study to evaluate the clinic-pathological spectrum of the biopsied cases, complications related to renal biopsy and its effect on management of paediatric renal diseases.

\section{METHODS}

This study was conducted in Paediatric Department of a referral centre in Eastern Nepal. All the patients undergoing renal biopsy and meeting the inclusion criteria during the study period from April 2019 to March 2020, were enrolled in the study. The study was approved from Institutional Ethical Committee (IRC 1504/019). Indications for renal biopsy were Steroid Resistant Nephrotic Syndrome (SRNS), Nephrotic Syndrome with age less than one year or more than 10 years or those with systemic features like (fever, rashes, joints pain, weight loss), before prescribing calcinuerin inhibitor in NS, Rapidly Progressive Glomerulonephritis (RPGN), lupus nephritis, unexplained nephrotic range proteinuria, persistent proteinuria $>$ two weeks and gross hematuria $>$ two weeks or microscopic hematuria $>$ two years, unexplained acute kidney injury (AKI). Exclusion criteria were bleeding diathesis, uncontrolled hypertension, uncorrected anemia (Haemoglobin < $9 \mathrm{gm} / \mathrm{dl}$ ), solitary kidney, gross hydronephrosis, acute pyelonephritis, large or multiple cysts, established end stage renal disease (ESRD) and parents refusing to participate. Nephortic syndrome was defined as presence of all features of nephrotic syndrome (edema, serum cholesterol $>200 \mathrm{mg} / \mathrm{dl}$, serum albumin $<2.5 \mathrm{gm} / \mathrm{dl}$ and urinary protein by dipstick $\geq 3+$ or $24 \mathrm{hr}$ urinary protein excretion $\geq 1$ $\mathrm{gm} / \mathrm{m}^{2}$ ) along with any features of nephritis like hypertension, elevated serum creatinine or hematuria. Nephritic nephrotic syndrome was defined as those having predominantly features of acute glomerulonephritis like hypertension, hematuria (gross or microscopic) and reduced urine output along with decrease glomerular filtration rate and also have one or more laboratory features of nephrotic syndrome. All other clinical terminology and definition have their usual standard meaning commonly used in literature.

Before performing renal biopsy, a complete blood count, renal function test, coagulation profile (prothrombin time, activated partial thromboplastin time), blood grouping and cross matching and USG of kidney, ureter, and bladder (KUB) was done. Written consent was taken from parents. Patients were kept nil per oral for $4 \mathrm{~h}$, bladder were emptied before biopsy. Biopsies were carried out in a wellequipped procedure room in the Radiology Department. In patients less than 10 years, sedation was done with injection midazolam, if required Ketamine or Fentanyl was also given. 2\% lignocaine with adrenaline was infiltrated in the area prepared to insert the biopsy needle. Renal biopsy was done under USG guidance from the lower pole of the left kidney using 18 gauze Bard biopsy gun under strict aseptic precaution.

Specimens were checked for adequacy of tissue. Two cores of tissues were obtained: one of them was kept in normal saline or Michelle solution for immunofluorescence microscopy and another one in formalin for light microscopy. Pressure bandage was applied at the site of biopsy. Patients were transferred to the Paediatric ward and were monitored carefully for pulse rate, blood pressure, respiratory rate, urine output, gross hematuria, local bleeding, and features of any other complications such as vasovagal shock, pain etc. Intravenous tramadol was given for any complain of pain. Routine USG of KUB was performed to detect any perirenal hematoma after six hours post biopsy.

Data regarding indication of renal biopsy, immediate complication during and after the procedure, clinical diagnosis and management and 
their variation post renal biopsy report was recorded in a predesigned pro forma and then entered in Microsoft Excel. The data was transferred to Stata IC 14.0 for analysis. Descriptive statistics was used to describe the demographic, clinical data, laboratory profile and outcome variables of enrolled children.

\section{RESULTS}

There were 50 renal biopsies performed during the study period, with age ranging from two years to 16 years and a mean age of $10.3 \pm 3.1$ years. The female to male ratio was 1.1. Based upon the presentation, the commonest indications for renal biopsy were acute nephritic syndrome (50\%), followed by nephrotic syndrome (36\%), as depicted in (Figure 1).

Acute nephritic syndrome comprised of 11 cases of primary glomerulonephritis and 14 cases of secondary glomerulonephritis (lupus nephritis and Henoch Schonlein Purpura nephritis); lupus nephritis was the commonest $(11 / 25)$. In lupus nephritis, majority had pathological classification of class IV with or without class V (6/11). Most cases presenting with nephritic nephrotic syndrome had diffuse proliferative glomerulonephritis

Table 1. Renal biopsy findings with predominant clinical presentation of acute nephritic syndrome $(\mathrm{n}=25)$

\begin{tabular}{|c|c|c|c|}
\hline $\begin{array}{l}\text { Acute } \\
\text { Nephritic } \\
\text { Syndrome }\end{array}$ & $\begin{array}{c}\text { Renal Biopsy } \\
\text { Diagnosis }\end{array}$ & Frequency & $\begin{array}{c}\text { Net } \\
\text { Frequency }\end{array}$ \\
\hline \multirow{4}{*}{$\begin{array}{l}\text { Lupus } \\
\text { Nephritis* }\end{array}$} & Class II & 3 & 11 \\
\hline & Class III & 2 & \\
\hline & Class IV & 4 & \\
\hline & Class IV + V & 2 & \\
\hline \multirow{3}{*}{$\begin{array}{l}\text { Nephritic } \\
\text { Nephrotic }\end{array}$} & DPGN & 7 & 8 \\
\hline & C3 GN & 1 & \\
\hline & Crescentic GN & 1 & 3 \\
\hline RPGN & $\begin{array}{l}\text { DPGN + Focal } \\
\text { Crescents }\end{array}$ & 2 & \\
\hline \multirow{2}{*}{$\begin{array}{l}\text { HSP } \\
\text { Nephritis** }\end{array}$} & M0E1S1T0C0 & 2 & 3 \\
\hline & M1E1S0T0C0 & 1 & \\
\hline $\begin{array}{l}\text { ('International } \\
\text { classification for } \\
\text { Glomerulonephr } \\
\text { C3GN-Complet } \\
\text { Classification fo }\end{array}$ & $\begin{array}{l}\text { itis, DPGN-Diffuse } \\
\text { ment } 3 \text { Glomerul } \\
\text { r HSP Nephritis(7)) }\end{array}$ & $\begin{array}{l}\text { oliferative Glon } \\
\text { ephritis, } \quad * * U_{P}\end{array}$ & $\begin{array}{l}\text { hology Society } \\
\text { dly Progressive } \\
\text { nerulonephritis, } \\
\text { pdated Oxford }\end{array}$ \\
\hline
\end{tabular}

(DPGN) pattern, (7/8) indicating a post-infectious etiology. The other indications were rapidly progressive glomerulonephritis (RPGN) and HSP Nephritis (Table 1). Only one of three cases which had clinical presentation of RPGN had crescentic glomerulonephritis and remaining had DPGN (post-infectious infectious etiology).

Secondly, $36 \%$ of the cases which underwent biopsy had nephrotic syndrome, of which SRNS, age $>10$ years and nephrotic nephritic syndrome comprised seven cases and three cases each respectively. Five of the cases with steroid dependent course underwent biopsy before starting Calcineurin inhibitors. SRNS mostly had pathological pattern of Minimal Change Disease (MCD) (4/7) whereas all of the cases with clinical nephrotic nephritic syndrome had IgA nephropathy (Table 2).

Out of four cases with severe AKI, two were drugs induced; the pathological pattern was of severe acute tubular interstitial nephritis (ATIN) in three cases and one case had pattern suggestive of thrombotic microangiopathy (TMA), which was diagnosed as atypical haemolytic uremic syndrome. Among acute kidney disease (AKD), two had diffuse global glomerular sclerosis (DGGS) and one had chronic glomerular nephritis (CGN). The indications for renal biopsy and related

Table 2. Renal biopsy findings with predominant presentation of nephrotic syndrome $(n=18)$

\begin{tabular}{|c|c|c|c|}
\hline $\begin{array}{l}\text { Nephrotic } \\
\text { Syndrome }\end{array}$ & $\begin{array}{c}\text { Renal Biopsy } \\
\text { Diagnosis }\end{array}$ & Frequency & $\begin{array}{c}\text { Net } \\
\text { Frequency }\end{array}$ \\
\hline \multirow[t]{2}{*}{ SRNS } & $\mathrm{MCD}$ & 4 & 7 \\
\hline & FSGS & 3 & \\
\hline \multirow{2}{*}{$\begin{array}{l}\text { Pre CNI } \\
\text { (SDNS) }\end{array}$} & MCD & 4 & 5 \\
\hline & DSGS & 1 & \\
\hline \multirow{2}{*}{$\begin{array}{l}\text { NS age }> \\
\text { 10yrs }\end{array}$} & FSGS & 2 & 3 \\
\hline & MCD & 1 & \\
\hline \multirow{4}{*}{$\begin{array}{l}\text { Nephrotic } \\
\text { Nephritic }\end{array}$} & $\operatorname{Ig} \mathrm{A}$ & & 3 \\
\hline & Nephropathy* & & \\
\hline & M1E1S0T0C1 & 2 & \\
\hline & M1E1S0T0C0 & 1 & \\
\hline \multicolumn{4}{|c|}{$\begin{array}{l}\text { (*Oxford Classification of IgA Nephropathy, SRNS - Steroid } \\
\text { Resistant Nephrotic Syndrome, MCD - Minimal Change Disease, } \\
\text { CNI-Calcineurin Inhibitor, NS - Nephrotic Syndrome, FSGS-Focal } \\
\text { Segmental Glomerulosclerosis, DSGS - Diffuse Segmental } \\
\text { Glomerulosclerosis) }\end{array}$} \\
\hline
\end{tabular}


Table 3. Biopsy findings among acute kidney injury and acute kidney disease $(n=7)$

\begin{tabular}{|llcr|}
\hline $\begin{array}{l}\text { Indication } \\
\text { for Renal } \\
\text { Biopsy }\end{array}$ & $\begin{array}{c}\text { Renal } \\
\text { Biopsy } \\
\text { Diagnosis }\end{array}$ & Frequency & \multicolumn{1}{c|}{$\begin{array}{c}\text { Net } \\
\text { Frequency }\end{array}$} \\
\hline AKI - III & TMA & 1 & 4 \\
& ATIN & 3 & 3 \\
AKD - III & DGGS & 2 & \\
& CGN & 1 & \\
\hline
\end{tabular}

(AKI - Acute Kidney Injury, AKD - Acute Kidney Disease, TMA Thrombotic Microangiopathy, ATIN - Acute Tubular Interstitial Nephritis, DGGS - Diffuse Global Glomerulosclerosis, CGN Chronic Glomerulonephritis)

pathological findings are summarised in (Table 3). Among two cases with AKD, the cases had steroid dependent nephrotic syndrome, but later had persistent elevation of serum creatinine for which a biopsy was done which revealed DGGS. One case in AKD had presentation like PIGN but had persistently deranged kidney function, which on biopsy turned to have chronic GN.

The procedural complication of USG guided renal biopsy was found in (8/50) cases. All of them had self-resolving gross haematuria, which took 48 to 72 hours for resolution. Among these eight cases, one had perirenal haematoma with hemodynamic instability requiring transfusion requiring plasma and packed cell transfusion. In one case, there was sampling error as both the samples did not contain renal tissue. While in the other two cases, one of the biopsied core contained only renal medulla tissue. All these three cases underwent repeat renal biopsy in an interval of three to four weeks post first biopsy and there were no complications later.

Immunosuppressive therapy was altered in 18 $(36 \%)$ cases. In 12 cases (DPGN without crescents and with post infectious etiology - seven cases, three cases with HSP nephritis and two cases with DGGS), the need of immunosuppression was not indicated after renal biopsy and steroid was tapered and stopped. Among six cases (Four SLE nephritis which clinically was thought to have low grade nephritis which on biopsy turned to have high severe form, one crescentic $\mathrm{GN}$ and one $\mathrm{C}_{3} \mathrm{GN}$ ) more aggressive immunosuppressive therapy was planned following the report.

\section{DISCUSSION}

This study highlighted the importance of performing kidney biopsy in children among the indicated cases. The biopsy was performed in the age group of two to 16 years under ultrasound guidance and with the use of sedation for those less than 10 years. Among acute nephritic syndrome, the commonest indication for renal biopsy was for staging lupus nephritis, so that precise staging and hence the management and prognosis could be done. Similarly, the commonest pathological finding among nephritic nephrotic syndrome was DPGN, reflecting the underlying post infectious pathology. Among nephrotic syndrome, the common indications for biopsy were mostly SRNS and pre Calcineurin inhibitor therapy, more than half of these cases had minimal change pathology. The procedure was found to be safe with transient haematuria in $16 \%$ of the cases, only one case developed serious complication of perirenal haematoma requiring transfusion of blood products. There were no anaesthetic related complications observed in any of the cases. In addition, renal biopsy helped in deciding the choice of immunosuppressive agent as well as its discontinuation in selective cases.

In regards to similar studies in the past, Sahney et al. evaluated the indications and complications of native kidney biopsy among 34 children, where they found that in (26/34) cases, biopsy was indicated for nephrotic and nephritic syndrome, with equal contribution from each. This was similar to our study. However, none of their cases had gross haematuria and only reported procedural complication was mild lower back pain in two cases. ${ }^{9}$ In another study, only (3/30) cases had complications like pneumonia secondary to immobilisation, peritonitis and minimal parenchymal haemorrhage in each of the cases. ${ }^{10}$ Similarly, in yet another study, the most common indication for renal biopsy was nephrotic syndrome (34.7\%), followed by nephritic nephrotic syndrome (20\%). Minimal change disease was the commonest pathological findings among nephrotic syndrome and among non-nephrotic primary glomerulonephritis, IgA nephritis was the commonest findings. ${ }^{11}$ The reason could be the occurrence of significant number of cases of PIGN in the Eastern Nepal. ${ }^{12}$ 
Santangelo et al. shared 36 years experience with 213 children, where they found that the most common indication for renal biopsy was NS (44.4\%) and the most common renal biopsy diagnosis was primary glomerulonephritis $(61.4 \%)$, followed by secondary glomerulonephritis like lupus / HSP nephritis. The most common histopathological diagnosis was IgA nephropathy $(20.9 \%)$ followed by minimal change disease $(18.1 \%)$. In $4.5 \%$ of the cases, adequate renal sample could not be obtained. The failure rate of obtaining sample is low and is equivalent to our study. However, the variation in indication and pathological findings could be due to differences in clinico - epidemiological and geographical profile. ${ }^{13}$

In another study involving renal biopsy in 123 children, the commonest indication was nephrotic syndrome $(58.5 \%)$, the result would be similar if in this study primary and secondary glomerulonephritis was not grouped into acute nephritic syndrome. In the same study the commonest pathological findings was mesangial proliferative glomerulonephritis (MesPGN), followed by MCD. The post biopsy hematuria was unduly high in this study (90\%), however similar to our study only, $1.6 \%$ required blood transfusion. The adequacy of renal tissue was (95\%) similar to our study. ${ }^{11,14}$

Post renal biopsy, the knowledge of exact renal pathology results in either discontinuation of corticosteroids, or continuation of corticosteroids along with addition of cytotoxic or alternate immunosuppressive agents in significant number of cases. In our study immune modulation was required in $36 \%$ of the cases, there are studies where the change in therapy was observed in 20 $34 \% .{ }^{14,15}$ We have tried to highlight the role of renal biopsy in the management of paediatric renal diseases. However, this is a relatively smaller sized study conducted in a single centre. We have not also followed up our cases for long term outcome. Although this study has tried to shed some light upon the role of renal biopsy in paediatric renal disorders, further larger and more collaborative studies are warranted in the future which would be more helpful to elucidate the role of renal biopsy in paediatric renal disorders.

\section{CONCLUSIONS}

Although performing renal biopsy in children is apprehensive to both parents and clinician, this study concluded that the ultrasound guided percutaneous renal biopsy is a safe, reliable and effective investigatory technique. Renal biopsy could give the precise pathology occurring in the kidney and helped in staging the diseases, resolute the diagnostic dilemma and guide in making therapeutic changes. Hence, renal biopsy should be considered in all the indicated cases in children with renal diseases.

\section{REFERENCES}

1. Burstein DM, Schwartz MM, Korbet SM. Percutaneous renal biopsy with the use of real-time ultrasound. Am J Nephrol. 1991;11(3):195-200. DOI:https://doi.org/10.1159/000168303

2. Korbet SM. Percutaneous renal biopsy. Vol. 22, Semin Nephrol. W.B. Saunders; 2002.22(2)254-67. DOI: https:// doi.org/10.1053/snep.2002.31713

3. Brachemi S. Renal biopsy practice: What is the gold standard? World J Nephrol. 2014;3(4):287. DOI: https:// doi.org/10.5527/wjn.v3.i4.287

4. Stratta P, Canavese C, Marengo M, Mesiano P, Besso L, Quaglia M, et al. Risk management of renal biopsy: 1387 Cases over 30 years in a single centre. Eur J Clin Invest. 2007 Dec;37(12):954-63. DOI: https://doi.org/10.1111/j. 1365-2362.2007.01885.x 
5. Varnell CD, Stone HK, Welge JA. Bleeding complications after pediatric kidney biopsy: A systematic review and meta-analysis. Clin J Am Soc Nephrol. 2019 Jan;14(1):57-65. DOI: https://doi.org/10.2215/CJN.05890518

6. Bajema IM, Wilhelmus S, Alpers CE, Bruijn JA, Colvin RB, Cook HT, et al. Revision of the International Society of Nephrology/Renal Pathology Society classification for lupus nephritis: clarification of definitions, and modified National Institutes of Health activity and chronicity indices. Kidney Int. 2018 Apr;93(4):789-96. DOI: https:// doi.org/10.1016/j.kint.2017.11.023

7. Huang X, Ma L, Ren P, Wang H, Chen L, Han H, et al. Updated Oxford classification and the international study of kidney disease in children classification: application in predicting outcome of Henoch-Schönlein purpura nephritis. Diagn Pathol. 2019 Dec;14(1):40. DOI: https://doi.org/10.1186/s13000-019-0818-0

8. Trimarchi H, Barratt J, Cattran DC, Cook HT, Coppo R, Haas M, et al. Oxford Classification of IgA nephropathy 2016: an update from the IgA Nephropathy Classification Working Group. Kidney Int. 2017 May;91(5):1014-21. DOI: https://doi.org/10.1016/j.kint.2017.02.003

9. Sahney S, Mohan GC. Renal Biopsy in Infants and Children. Am J Kidney Dis. 1994;23(1):31-2. DOI: https:// doi.org/10.1016/S0272-6386(12)80808-0

10. Hod Feins R, Tobar A, Davidovits M. Yield and complications of kidney biopsy over two decades in a tertiary paediatric center. Pediatr Int. 2017 Apr;59(4):452-7. DOI: https://doi.org/10.1111/ped.13182

11. Shrestha D, Dhakal AK, Basnet NB, KC SR, Kafle RK. Histopathological audit of renal biopsy in Nepalese children: two center experience. J Pathol Nepal. 2018;8(1):1244-50. DOI: https://doi.org/10.3126/jpn.v8i1.19443

12. Yadav SP, Shah GS, Mishra OP, Baral N. Pattern of renal diseases in children: A developing country experience. Saudi J Kidney Dis Transpl. 2016;27(2). DOI: https://doi.org/10.4103/1319-2442.178565

13. Santangelo L, Netti GS, Giordano P, Carbone V, Martino M, Torres DD, et al. Indications and results of renal biopsy in children: a 36-year experience. World J Pediatr. 2018 Apr;14(2):127-33. DOI: https://doi.org/10.1007/ s12519-018-0147-5

14. Roy RR, Al Mamun A, Haque SMS, Muinuddin, G, Rahman MH. Role of Renal Biopsy in Managing Pediatric Renal Diseases : A Mid- term Analysis of a Series at Bangabandhu Sheikh Mujib Medical.Saudi J Kidney Dis Transpl. 2017;28(1):125-32. DOI: https://doi.org: 10.4103/1319-2442.198164

15. Cohen AH, Nast CC, Adler SG, Kopple JD. Clinical utility of kidney biopsies in the diagnosis and management of renal disease. Am J Nephrol. 1989;9(4):309-15. DOI: https://doi.org/10.1159/000167986 